\title{
Letter to the Editor: Role of Chewing Gum in Reducing Postoperative Ileus after Reversal of Ileostomy: A Randomized Controlled Trial
}

\author{
Paweł Konstanty Korolkiewicz ${ }^{1}$. Lukasz Sein Anand ${ }^{1}$
}

Accepted: 20 February 2021 / Published online: 1 April 2021

(C) Société Internationale de Chirurgie 2021

\section{Dear Editor,}

It is with great interest that I read the study of Bhatti et al. [1] on the effects of chewing gum on the duration of postoperative ileus (POI) in patients undergoing surgery for stoma closure and small gut anastomosis.

I would like to draw your attention to some confounders, which should be taken into consideration while interpreting the results of the study.

The prolonged administration of antimycobacterial agents including a relatively broad-spectrum antibiotic such as rifampin exerts a profound effect on the gut microbiome [2]. The iatrogenic microbial dysbiosis could negatively affect gastrointestinal and colonic motility [3] and might have played a potential role in the delayed POI resolution time in the tuberculosis versus typhoid perforation cohorts—-see Table 5 for results [1].

Additionally, the study is an investigator-sponsored trial, and all patients were recruited at a single research site, thereby reducing the generalizability of these interesting and valuable results.

Paweł Konstanty Korolkiewicz

pawelkorolkiewicz@gumed.edu.pl

1 Medical University of Gdańsk, Poland. Address: Debinki 7, 80-952 Gdańsk, Poland

\section{Compliance with Ethical Standards}

Conflict of interest The authors declare that they have no conflict of interest.

\section{Reference}

1. Bhatti S, Malik YJ, Changazi SH, Rahman UA, Malik AA, Butt UI, et al. Role of Chewing Gum in Reducing Postoperative Ileus after Reversal of Ileostomy: A Randomized Controlled Trial. World J Surg [Internet]. 2021; Available from: https://doi.org/10. 1007/s00268-020-05897-1

2. O'Toole RF, Gautam SS. The host microbiome and impact of tuberculosis chemotherapy. Tuberculosis [Internet]. 2018;113:26-9. Available from: https://doi.org/10.1016/j.tube. 2018.08.015

3. Ge X, Ding C, Zhao W, Xu L, Tian H, Gong J et al (2017) Antibiotics-induced depletion of mice microbiota induces changes in host serotonin biosynthesis and intestinal motility. J Transl Med 15(1):1-9

Publisher's Note Springer Nature remains neutral with regard to jurisdictional claims in published maps and institutional affiliations. 